\title{
LAS INSTITUCIONES DE EDUCACIÓN SUPERIOR A DISTANCIA EN IBEROAMÉRICA
}

La presencia y consolidación de la educación superior en Iberoamérica es una realidad incontestable. Diferentes acontecimientos (políticos, económicos, sociales, tecnológicos, etc.) han coincidido en el tiempo, haciendo posible, poco a poco, una oferta formativa de calidad a una creciente demanda de educación superior. Pero esta exigencia reclama también una formación más acorde con las necesidades cada vez más cambiantes de nuestra sociedad, una educación permanente que forme a todo ciudadano en las diferentes etapas de la vida, y una educación que no esté condicionada por las limitaciones temporales y espaciales propias de todo profesional. En consecuencia, estamos planteando a la educación, y específicamente al nivel universitario una respuesta que "(...) exige cambios importantes en su estructura y funcionamiento internos, así como en la dinámica de su proyección hacia la sociedad” (Silvio, 2004, p. 15).

Si revisamos la historia de la universidad en Latinoamérica, comprobamos cómo ésta ha evolucionado de la mano de los hitos de la universidad europea. Los avances, los errores, las expectativas y los fracasos han corrido de forma paralela entre ambos continentes. Sin duda, la realidad de todos estos países latinoamericanos ha sido como el comportamiento de vasos comunicantes, en el que el efecto de cada decisión en política universitaria ha afectado como motor y, en ocasiones, también como ralentizador en el desarrollo de este nivel educativo, en todos estos países.

Y si nos fijamos en la acogida que este continente ha dispensado a la educación a distancia, la historia evolucionó no de forma muy distinta a la europea. La extensión y reconocimiento de la educación a distancia en el ámbito universitario no ha sido sencilla. Han sido pocas universidades, comparativamente hablando con el número de instituciones universitarias presenciales reconocidas en este hemisferio, las que plantearon, allá por la década de los 70 del pasado siglo XX, una auténtica revolución e innovación educativa: la formación a distancia de titulados superiores.

La apuesta en esos momentos era muy arriesgada, máxime si contamos con unos medios de comunicación que aún no posibilitaban un contacto inmediato y directo entre profesores y alumnos. A pesar de esta inicial y aparente carencia, la aventura por la formación universitaria a distancia comienza y, en pocos años, se consolida como una alternativa válida para miles de estudiantes. Ejemplo de esta realidad son instituciones tan reconocidas actualmente, y que superan en la actualidad todas ellas más de veinte años de experiencia, como es el caso de la UNED de España, UNA de Venezuela, UNAM de México, UTPL de Ecuador, UNAD de Colombia, UNED de Costa Rica y un largo etcétera que apostaron, sin poder contar aún con las inmensas posibilidades que hoy en día nos 
brindan las tecnologías, por una formación de calidad en un entorno a distancia.

Los años de las décadas de los 70 y los 80 fueron decisivos para la consolidación de la educación a distancia en el nivel universitario, años en los que se pudo dejar ya asentadas unas bases sólidas que, fechas más tarde, posibilitarían la irrupción de otras muchas instituciones en la educación superior con entornos virtuales de aprendizaje. Ahora nuestra mirada se centra en la educación virtual, en las inmensas posibilidades que nos está ofreciendo, en las experiencias transnacionales que están surgiendo gracias a ella, en las innovaciones tecnológicas que, día a día, abren nuevas alternativas de formación rompiendo toda barrera espacial y temporal. Sin embargo, en esta espiral de innovación, es necesario no perder de vista los fundamentos que dan sentido y explican el por qué y el para qué de esta metodología. Este es el sentido y objeto de este monográfico, que pretende aportar las claves de los indicadores de calidad de toda propuesta educativa, ya que "del mismo modo, quienes intentan diseñar modelos avanzados de educación a distancia, enfocando sólo la información acerca de sus componentes teóricos y/o tecnológicos parecen suponer que así llegarán a donde quieren ir de la manera más directa. Sin embargo, dejan de lado todo lo que está cerca de los bordes: la historia, el contexto, las expectativas de los actores, los recursos, etcétera. Todos estos, componentes de significación que ofrecen amplitud de visión y marcan opciones otorgándole un sentido a la información" (Mena, 2004, p. 17). Para ello, y cómo vía de reflexión, presentamos algunas de las instituciones de educación superior que iniciaron la oferta de estudios superiores a distancia antes de la explosión de las tecnologías de la información y la comunicación. Todas ellas son claves para entender la evolución de la educación a distancia en Latinoamérica.

Ahora bien, debemos destacar que en este monográfico no están presentes todas ellas, pero esperamos poder ofrecer un segundo volumen monográfico en las que sigamos recogiendo las experiencias de indudable valor de todas estas instituciones, de tal forma que podamos completar el panorama que estamos ofreciendo. A lo largo de cada artículo, cada institución, respetando su forma peculiar de exponer su propia historia y su proyecto vital, concreta su recorrido histórico, va desvelando su concepción de la educación a distancia, los ámbitos prioritarios en los que se desarrolla, la metodología en la que se apoya, los proyectos innovadores que están promoviendo, las acciones que ha llevado a cabo, y, de forma, singular, los proyectos de futuro. No hay un mismo esquema de trabajo, aunque si existe una misma seña de identidad: la apuesta por una formación universitaria de calidad.

Otro punto de conexión entre todas estas instituciones universitarias es que todas ellas pertenecen a la Asociación Iberoamericana de Educación Superior a Distancia (AIESAD). Estamos ante la primera asociación de este tipo, promovida en 1980, que se creó con el fin de crear un mecanismo permanente de información, coordinación y 
cooperación entre todas ellas y en beneficio de los pueblos latinoamericanos. La única institución universitaria de este volumen que no pertenece a esta Asociación es la Universitat Oberta de Catalunya (UOC), institución que comienza, además, su andadura apoyada íntegramente en las tecnologías de la información y comunicación. Su inclusión en este monográfico se debe al importante papel que ha cumplido tanto en el desarrollo y consolidación de la educación a distancia en el nivel superior, como en la expansión de este modelo en Iberoamérica.

Las otras instituciones presentes aparecen de acuerdo al orden cronológico en el que iniciaron la oferta de estudios universitarios a distancia: UNED, España; IITD, España; USTA, Colombia; UTPL, Ecuador; UNED, Costa Rica; Universidad de La Habana, Cuba; UNMdP, Argentina; PUCP, Perú; UAPA, República Dominicana; UPS, Ecuador; UNISINOS Brasil. Todas ellas de reconocida trayectoria en el ámbito de la educación a distancia. Sin su aportación, difícilmente se entendería la educación a distancia Iberoamericana en estos momentos, en el que, sin duda, es imposible encerrar en un único escenario, ni con un único perfil (Mena, 2004).

A partir de todo este recorrido, podremos valorar realmente que es educación a distancia y su papel en la formación universitaria, las claves educativas que supone todo proyecto innovador y, de forma especial, nos ayudará a valorar las nuevas experiencias de formación, a diferencias realmente cuáles son las claves de una formación a distancia, sin dejarnos cegar por las tecnologías, verdaderos fuegos artificiales que deslumbran, pero que, en muchas ocasiones, adolecen de las claves reales de toda educación. Y, de forma especial, a valorar las realidades diferentes de cada país, donde continúan conviviendo tiempos y modelos de formación diferentes, y en los que la educación a distancia nos ayudará, sin duda, a intentar ofrecer una mejor formación a todos los sectores de esta rica población.

Marta Ruiz Corbella, UNED, España $M^{a}$ José Rubio Gómez, UTPL, Ecuador

Coordinadoras del Monográfico

\section{REFERENCIAS BIBLIOGRÁFICAS}

Mena, M. (comp.) (2004). La educación a distancia en América Latina. Modelos, tecnologías y realidades. Buenos Aires: La Crujía.

Silvio, J. (2004). Tendencias de la educación superior virtual en América Latina y el Caribe. En: ANUIES La educación superior virtual en América Latina y el Caribe. México: ANUIES, 15-38. 